\title{
Research on Dissemination Mechanisms of Marxism Popularization in Big Data Era
}

\author{
Huimin Li \\ China University of Mining \& Technology, Beijing, Beijing, 100083, China
}

Keywords: Marxism popularization; dissemination mechanisms; big data era

\begin{abstract}
At present, big data is triggering a great change in the dissemination model. The advent of the era of big data has brought about Marxism popularization many opportunities, such as expanding dissemination subjects, broadening dissemination channel and enhancing dissemination effect. Under the background of big data era, it is necessary to make full use of the big data technology to excavate dissemination audience, innovate dissemination forms and improve supervision mechanism to strengthen the effect of Marxism popularization.
\end{abstract}

\section{Introduction}

In the era of big data, the fragmented information has shown an exponential growth trend [1]. Facing the deep influence of surging and big data, the Internet is not only a virtual world, but a real space for people to express their demands. The Internet should also become an indispensable platform for teaching. Big data is read on a wide variety of massive data effectively capture, management, integration, analysis, scientific and empirical support for the creation of new value, to promote the development of information technology, and as a kind of values and methodology are widely used in various fields, to guide practice and service practice. It has benefited from the strong support of information, network, cloud computing, and big data. The collection, calculation and application of massive data has promoted the service of big data to the life, production and scientific research of human society. Big data contains a wealth of scientific and social values, as the core competitiveness of a new era, Marx's workers should also be positive action, to further enhance the scientific discipline, provide the guidance of the new paradigm a new method of generating new tools, make full use of the characteristics of big data for the Marx doctrine spread, better thinking a spark of the collision to create conditions. The big data value of the cloud computing platform leads and serves the country, the enterprise and the individual, and is also an important carrier of the ideological and political education. At present, it is not only of theoretical significance but also of important application value to study the carrier of big data ideological and political education. The basic theory of connotation, systematic studies on big data carrier of Marxism popularization of the characteristics, function, form, function, construction of big data carriers and Marx's framework of interdisciplinary organic system, which can achieve interactive platform penetration and education dissemination [2].

\section{Opportunities of Marxism Popularization Brought by Big Data Era}

\subsection{Expand Dissemination Subjects.}

China is a socialist developing country. It has been slightly inferior to those developed countries in the West in terms of big data technology development and global media network. The diversity of big data has led to diversified development of people's values. All contents are full of every hue in the network, but there are some bad doping negative views, they will mislead people's government departments in the dissemination of mainstream value outlook on knowledge and understanding of errors. In addition, open big data also provides spread in the network the opportunity for people of different cultures, to some extent exacerbated the cultural conflict and confrontation between 
different ideologies, the mainstream value outlook of China's ability to affect people further weakened, to some extent hindered the realization of spread of the Marx doctrine China target. The equality of the great data age expands the main body of Marx's spread. The value of theory is not to be put on the shelf, but to guide practice and to the extent of guiding practice. The theory cannot be separated from the spread, and Marx's doctrine is no exception. Historically, Marx spread more orthodox Marx doctrine creators, developers, interpreters and practitioners, playing the role of image spokesman. But in the big data age, everyone can become a representative. Everyone is the contributor to the data and the disseminator of the information, and everyone is the subject of equality. In this free space information network, and between the docking and the relations between people and people, information and information between the collision is infinite possibility to promote, each person makes the data in the message, Marx's theory of life, is popular in the process, is accepted by more the people, thus strengthening the Marx theory of dissemination subject [3].

\subsection{Broaden Dissemination Channel.}

For a long time, the spread of Marx is mainly delivered by the mass media, such as print media, broadcast media, television and other medias [4]. The essence has not touched Marx's dissemination. In the era of big data, social media, such as micro-blog and WeChat, have developed continuously, and the interpersonal media and information media have merged. Social media is the product of its integration. It breaks the unity and limitations of traditional media, broadens people's dissemination channels, and develops people's dissemination ability. This two-way interaction mode will become an effective channel for Marx's dissemination. We should make full use of the role of the Internet media. As an important tool for science and technology to influence society, the network provides a platform for all kinds of ideological concepts and ideology to compete for ideological space. We should make full use of the characteristics of the huge information capacity of the Internet and convenient and quick inquiry, to broaden the strength of Marx's education. Actively to education theme, content and requirements into specific network context, through online chat, discussion, demonstration, evaluation, publicity and other forms of the mainstream ideology education more authenticity, inspiration and situational, ideology, knowledge, interest and vividness in one. We should make use of social practice to promote the popularization of Marx's doctrine. Social practice is an important carrier and bridge from theoretical cognition to theoretical practice. Therefore, we should carry out more social practice activities and mobilize the inner enthusiasm of self - education and self management through social practice activities. The popularization of Marx's doctrine is the unification of the unity of truth and value, the law of conformity and the purpose of unity. In the process of Marx's popularization, we should not only fully display the truth charm of Marx's law, but also show the charm of value rationality that represents the fundamental interests of the people.

\subsection{Enhance Dissemination Effect.}

In the era of big data, the speed of data dissemination is fast and the time limit is high, which has become a favorable opportunity for the popularization of Marx. The data transmission speed, for the first-time limitation, provided the dissemination efficiency. Through the popularization of Marx doctrine, we should try to help the masses of people establish a common sense of socialism, mobilize the enthusiasm and initiative of the masses in the socialist modernization drive, and finally achieve the Chinese dream. Through the popularization of Marx doctrine, we can make people overcome the confusion and firm position under the guidance of national development goals and ensure the right direction of dissemination. The era of big data is a new era, and several innovative talents are needed to carry out the popularization of Marx doctrine. Innovative people can tap the charm and potential of big data, and inspire them to further collect, store and recycle big data, and enhance the effectiveness of dissemination. In the era of big data, not only can we provide valuable data and information for the spread of Marx doctrine, but also bring more threats and challenges, which may cause adverse effects on privacy and tendencies. Therefore, the effective use of large data will cause large data to serve as a dissemination service. But in fact, we often focus on not only the basic uses of data, but also the two uses of data, which often leads to many innovative uses after two times of use. Especially Marx's 
mass dissemination process, too much emphasis on the basic use of data, may lead to the spread of the effect is not obvious, through the collection and analysis of data, used for the two time can predict the effect of the data, although the data cannot explain the causal relationship between, but will make the spread of targeted work, enhancing dissemination effectiveness.

\section{Dissemination Strategies of Marxism Popularization in Big Data Era}

\subsection{Excavate Dissemination Audience.}

As a scientific world outlook and methodology, The Marx doctrine is not a casual talk philosophy, not obscure speculative philosophy study, nor a student classroom textbook philosophy, but to change the world's practical philosophy, we should always pay attention to the hot topics and solve the problem of age, reflect the service. Therefore, the dissemination of Marx doctrine should not only disseminate specific contents, but also look for the attention points of Marx's audience, and then carry out targeted and personalized communication so as to improve the effectiveness of communication. This requires data mining algorithm based on big data to serve the audience, find the personalized needs of the audience, and then provide personalized service to the audience, so that the audience can be more recognized, understood and accepted. Specifically, on the one hand, we should protect the audiences' attention by matching the categories of the audiences by classifying the contents of Marx's dissemination, and using the data mining technology of big data to accurately locate the audience's concerns and establish the audience's central position. The popularization of Marx's doctrine needs several subjects mastering Marx's theory, that is, the educator who is engaged in the theory of Marx. Under the current situation, the popularization of Marx doctrine cannot be separated from the participation of Marx theory workers. Therefore, whether we can build a team of experts with deep level of Marx doctrine and high sense of political responsibility and lofty sense of mission is of great strategic significance to the spread of Marx doctrine, especially the theory of socialism with Chinese characteristics. The core of the big data is the prediction. It is the possibility that a mathematical algorithm is used to predict the occurrence of a large amount of data. The dissemination of Marx's doctrine in the present time should increase its effectiveness. In addition to consolidating the realistic audience, it should expand the scope of communication and capture the potential audience.

\subsection{Innovate Dissemination Forms.}

In the era of big data, the popularization of Marx's doctrine needs to be constantly combined with the characteristics of different historical stages to improve the efficiency of theory communication. Under the background of large data, the popularization of Marx doctrine should keep pace with the times, and the most important thing is to actively change the way of thinking of the communicators. In the new normal economic development under the guidance of Marx doctrine popular dissemination way of thinking, is conducive to improve the communication efficiency of the popularization of the Marx doctrine, enhanced mass communication effect, to consolidate the dominant position of Marx's thought, to better serve the economic development. In large data technology, it enriches the form of communication and improves the efficiency of communication. The popularity of Marx doctrine focuses on the integration of Marx's theory and mass practice. This combination requires precise combination and cannot be blindly propagated for communication. The data age is not obsessed with accuracy, to achieve the accuracy of the mass dissemination of Marx's content, improve the efficiency of communication and enhance the effectiveness of communication. The era of big data innovation, the Marx doctrine popularization work, to cultivate people's sense of innovation, give full play to the innovation ability, to flexibly and effectively grasp the new Marx doctrine popular communication technology, understand the latest theory of dynamic propagation of work and timely tracking, analysis and feedback, to achieve the development of innovative communication. It is urgent to cultivate professional innovative talents and break through the stereotyped creative talents. It is urgent to create a big data team that is willing to break the norm, especially in the process of popularization of Marx doctrine. The establishment of big data team 
should keep the sensitivity and openness of the mind, grasp the development trend of Internet and social media, actively absorb the advanced communication concept and the idea of public opinion, and accelerate the popularization process of Marx doctrine.

\subsection{Improve Supervision Mechanism.}

The popularization of Marx doctrine based on large data technology is a process of information interaction. Therefore, Marx's theory of communication subject should use new media technology, in an equal attitude, actively strengthen and the exchange of ideas, and guide users to interact, timely understand the thinking of the audience, collecting the network of public opinion, to effectively inspire the education of the masses, master Marx's mass communication the process and effect. The virtual nature of the interactive relationship has led to some people's political and moral consciousness. Network anomie has become an unavoidable problem in the process of information technology in China. Some netizens talk rubbish on the Internet, or even break malignant insult, abuse, causing some people especially teenagers and social values of fuzzy dilution, national consciousness is not strong, the decline of vulgar culture immunity, even to the western culture blindly worship, thus losing the ideals and beliefs. A variety of phenomena show that it is imperative to establish a network regulatory agency. In practice, the construction of network supervision mechanism, is to carry out timely guidance and feedback to our country ideology security of public opinion, penetration of foreign ideology resolutely and thoroughly counterattacks, strengthen and promote the basic principle of the Marx doctrine. We should coordinate and utilize all kinds of information network carriers to ensure the basic quality of the website and take advanced technical means to monitor the network when necessary. In Marx's mass communication process, on the one hand, through the Marx doctrine theory of propaganda, the masses of Marx's belief, social consensus; on the other hand, timely feedback to the aspirations of the masses, so that the Marx doctrine theory and meets the needs of the masses. The popularization is embodied in many aspects, such as the form of communication, the means of propaganda, the political stand of the party and the fundamental viewpoint. In the political position and fundamental view of the party, the party should always highlight the political leadership of the party in the work of communication. Therefore, it is reflected in the dissemination of the direction to further enhance the feasibility and effectiveness of the communication work. At the same time, to establish and perfect the laws and regulations of big data, investigate and punish acts of lawlessness, providing a healthy and orderly platform for the realization of the popularization of the Marx doctrine.

\section{Conclusion}

In the era of big data, we should make use of the advantages of the era of big data to grasp the good opportunity for the popularization of Marx's doctrine. We take advantage of big data and other science and technology to further consolidate the guiding position of Marx's scientific theory and strengthen Marx's belief of the masses, and work together to realize the Chinese dream.

\section{References}

[1] Yuan Xiaojie, JiaZhen. The dissemination strategies of the popularization of Marxismin the age of big data [J]. Journal of Liaoning Normal University (Social Science Edition), 2017, 40(3): 17-21.

[2] Huang Shijin. Big Data Era Graduate Students Explorethe Ideological and Political Theory Course Teaching Reform - Take the Chinese Marxisma nd the Contemporary as An Example [J]. Higher Education in Chemical Engineering, 2017(6): 94-98.

[3] Su Guoyun, Yin Junfang, Wang Zhizhong, et al. A Probe into Network Teaching in the Age of Big Data- A case study of the course Introduction of Basic Principles of Marxism [J]. Social Sciences Journal of Universities in Shanxi, 2015, 27(10): 46-49+54. 
[4] Jing Weiwei, Gong Jianhua. Popularization of Marxism in Era of New Media— Research on Discourse Conversion Based on Mass Disseminations, Journal of Bohai University (Philosophy \& Social Science Edition), 2017(6): 131-135. 